\title{
Ranging patterns of two syntopic gerbillid rodents: a radiotelemetry and live-trapping study in semi-desert habitat of Kalmykia, Russia
}

\author{
Andrei TCHABOVSKY, Joseph F. MERRITT and Dmitrii Y. ALEKSANDROV
}

Tchabovsky A., Merritt J. F. and Aleksandrov D. Y. 2004. Ranging patterns of two syntopic gerbillid rodents: a radiotelemetry and live-trapping study in semi-desert habitat of Kalmykia, Russia. Acta Theriologica 49: 17-31.

\begin{abstract}
We studied ranging patterns of syntopic folivorous and granivorous gerbils (Meriones tamariscinus Pallas, 1773 and Meriones meridianus Pallas, 1773, respectively) by means of radiotracking and live-trapping in Kalmykia, southern Russia. We hypothesized that ranging patterns exhibited by these rodents would differ in accordance with differences in their preferred diets. Trapping and radiotracking were performed from 23 May to 20 June 2000 on a 12 ha grid divided into $20 \times 20$ m squares. To assess ranging patterns we estimated the number of grid squares visited by an individual, $100 \%$ minimum convex polygon, mean squared distance from the center, maximal distance between individual locations, linearity index, and distance measures at various temporal scales. In accord with expectations, females of folivorous M. tamariscinus exhibited smaller ranges than females of granivorous $M$. meridianus. Contrary to our expectations both trapping and radiotracking data revealed similar "granivorous" ranging patterns in males of both species of gerbils. Male M. meridianus and M. tamariscinus were similar in number of burrows used, home range size, and distances traversed. No temporal dependence of distance measures was revealed in either species; males of both species traversed similar distances regardless of time interval for distance measures so that single-night movements and multiday movements did not differ in either species. High food selectivity in male M. tamariscinus is considered to be responsible for the "granivorous" pattern of space use in this folivorous species.
\end{abstract}

A. N. Severtsov Institute of Ecology and Evolution, 33 Leninskii pr., 119071 Moscow, Russia, e-mail: a.sadov@relcom.ru (AT, DYA); Carnegie Museum of Natural History, Powdermill Biological Station, HC64 Box 453, Rector, PA, USA,

e-mail: jmerritt@westol.com (JFM)

Key words: Meriones meridianus, Meriones tamariscinus, home range, movements; radiotelemetry, foraging

\section{Introduction}

Ranging patterns of mammals commonly correlate with feeding preferences and mating strategies of a species (McNab 1963, Mace and Harvey1983, Ostfeld 1985, 1990, Ribble and Stanley 1998, Kelt and Van Vuren 2001). Herbivores dependent on abundant low-quality food tend to have smaller ranges than omnivores of similar body size, which in turn exhibit smaller ranges than granivores that feed on widely dispersed scattered food items. Thus, quality, distribution and availability of 
preferred food items determine species ranging patterns in accord with species energetic requirements (Harestad and Bunnell 1979, Mace and Harvey 1983, Kelt and Van Vuren 2001). For example, among arvicoline species, strictly herbivorous voles Microtus arvalis exhibit very small ranges in contrast to large ranges of omnivorous Clethrionomys (Karulin et al. 1974). Food resources are assumed to affect spacing and ranging mainly in females, which in turn determines spacing and ranging in males (Glutton-Brock 1989, Ostfeld 1990, Davies 1991). In their study of two syntopic species of Peromyscus, Ribble and Stanley (1998) showed that home range size of males was positively correlated with dispersion of females. Home range size is also assumed to increase with body mass (Harestad and Bunnell 1979, Mace and Harvey 1983, Kelt and Van Vuren 2001). However, this general rule, based on the analysis of numerous species of birds and mammals, may be overshadowed by variation in resource distribution and habitat productivity when comparing closely related species (eg heteromyids - Reichman and Price 1993).

Numerous studies of desert rodents revealed a strong correlation between foraging habits and ranging patterns. In the Sahara Desert, intensive use of small drifting home ranges was shown, for example, in folivorous fat sand rats Psammomys obesus (Daly and Daly 1975). In the Karakum Desert, herbivorous great gerbils Rhombomys opimus move to new patches as food resources are depleted (Kucheruk et al. 1972). In the Negev Desert, another gerbillid species Meriones crassus dependent on green vegetation, was shown to regularly relocate small home ranges; during consecutive nights animals remained in close vicinity of a single burrow and then moved long distances to new burrows as food patches were exhausted (Krasnov et al. 1996). Such patterns of space use are characterized by alternation of series of consecutive short-distance recaptures with long-distance movements. Short-distance movements correspond to periods of residing within food patches while long-distance movements corresponding to relocations of foraging range (Krasnov et al. 1996).

Granivorous species of arid-adapted rodents show stable use of home ranges that covers more extensive areas. For example, in South Africa, granivorous gerbils Gerbilluruspaeba cover distances of hundreds of meters during the night searching for scattered food. Short-term (48 hours) and long-term (3 weeks) ranging distances do not differ (Ascaray and McLachlan 1990). Meriones meridianus, another granivorous gerbil from semideserts of the southern Russia, was reported to inspect their entire home range several times during a single activity phase (Popov et al. 1989). Individual home ranges remained stable from year to year and during the entire breeding season. This suggests that for granivorous species with extensive space-use, short-term ranging patterns overlap long-term patterns.

However, general rules predicting ranging patterns from the diet, mating system or body size, have numerous exceptions. For example, in contrast to the desert granivorous rodents of the Old World, heteromyids of the New World have very small home ranges (Reichman and Price 1993). Such discrepancy may be due to contrasting species that occupy different geographical areas, observed in different 
circumstances, and with quite different natural history attributes. The effect of diet, body size, mating system and other factors that affect ranging patterns may be, thus, confounded or misinterpreted due to the differences in habitat productivity or structure, timing of observations, and phylogenetical differences between species. Because the distribution and abundance of resources are important for ranging patterns, it is essential to compare closely-related species with different diets in the same location at the same time. Thus, syntopic and simultaneous observations of closely-related species seems the appropriate approach to analyze factors determining ranging patterns.

Midday gerbils Meriones meridianus Pallas, 1773 and tamarisk gerbils M. tamariscinus Pallas, 1773 are closely related species sympatric over a large part of their geographical range (Pavlinov et al. 1990). They inhabit desert and semi-desert areas of central Asia and of the southern European part of Russia. M. tamariscinus is a medium-sized (100-140 g) gerbil, while M. meridianus is relatively small (40-50 g). The species also differ in habitat preferences. Mesophilic M. tamariscinus is more specialized in habitat requirements and prefers well stabilized sands with tall and dense cover of perennial herbs, grasses and shrubs. Psammophilic M. meridianus is opportunistic and inhabits a wide spectrum of desert habitats. However, in contrast to M. tamariscinus, M. meridianus avoids closed habitats with dense vegetative cover (Pavlinov et al. 1990). Differences in habitat requirements between these species correspond to marked differences in their diets. M. tamariscinus is folivorous feeding mainly on green parts of perennial plants and flowers with high water content, whereas $M$. meridianus tends to be granivorous, dependent on seeds produced by ephemeral and perennial grasses and herbs (Pavlinov et al. 1990, Magomedov and Akhtayev 1993). Nevertheless, in Kalmykia (southern Russia) these gerbils occupy similar habitats that meet ecological requirements of both species (Tchabovsky and Aleksandrov 1996, Shilova et al. 2000). Both species are nocturnal and show similar patterns of spatial organization and male-female associations (Gromov et al. 1996). Home ranges of females usually overlap to a small extent, while large home ranges of males overlap extensively with those of females and among themselves. Both species show synchronous patterns of their reproductive cycle (Pavlov 1959). Breeding starts in March and ends in October with two periods of active reproduction in May-June and August-September.

We present results of radiotracking and trapping that elucidate ranging movements and burrow use in these two syntopic species of gerbils during the breeding season in Kalmykia, southern Russia. We hypothesized that ranging patterns exhibited by females would differ in accord with differences in species diets. Specifically we predicted that home ranges of granivorous $M$. meridianus would be greater than those of folivorous $M$. tamariscinus. Because both species exhibit similar spacing and mating systems, but differ drastically in the diet, we tested the prediction that feeding habits contribute to between-species differences in male ranging patterns. If true, we expected that distances moved by males during a 
A. Tchabovsky et al.

single-night activity phase (short-term ranging pattern) would be greater in granivorous M. meridianus than in folivorous M. tamariscinus and that the former would be found at greater distances from the day resting burrows than the latter. Further, we hypothesized that short-term (within a single activity phase) and long-term (multiday) ranging distances would be similar in M. meridianus, whereas in $M$. tamariscinus short distances moved during nighttime would alternate with longer distances of home range relocations. Overall, home ranges of M. tamariscinus would be less stable than those of M. meridianus.

\section{Material and methods}

\section{Field procedures}

The study was conducted from 23 May to 20 June 2000 in southern Kalmykia, Russia (45'29'N $45^{\circ} 26^{\prime} \mathrm{E}$ ). The area represents semi-desert with discontinuous vegetation of annuals (Poa, Bromus, Eremopiron), perennial grasses and herbs (eg Agropypon fragili, Stipa), forbs (Kochia prostata, Artemisia) and shrubs (Tamarix) on sandy or loamy soils (Neronov et al. 1997). The climate is continental with hot dry summers $\left(40\right.$ to $45^{\circ} \mathrm{C}$ in July) and cold ( -20 to $-30^{\circ} \mathrm{C}$ in January) winters characterized by minimum or no snow.

Capture-mark-recapture procedures were performed on a 12-ha grid divided into $20 \times 20 \mathrm{~m}$ squares with 300 trap stations. Gerbils were trapped during 12 consecutive nights in wire live-traps (100 by 100 by $300 \mathrm{~mm}$ ) baited with sunflower seeds with one trap per station. Animals were marked by toe-clipping. For each individual gerbil live-trapped we recorded species, sex, age, weight and location on grid. During the first 6 days of a trapping session 150 traps (one per square) were set in odd grid stations and then for the next 6 days traps were moved to even grid stations. Traps were set every evening just after sunset and run for 2-2.5 hours. On some nights, traps were checked twice to produce 10 monitoring episodes for each trap.

Radiotracking was performed concurrently with live-trapping and continued after conclusion of the trapping session. Only adult male gerbils were implanted with radiotransmitters. This was done so as to avoid negative effects of surgical procedure on females that were pregnant or lactating during the study. Small transmitters (2.5-3.3 g; SM1, AVM Instrument Company, Inc., Colfax, California) coated with "Elvax" (The Mini-Mitter Company, Inc. Sunriver, Oregon) were pretuned to a specific frequency ranging between 150-151 MHz. Gerbils were anaesthetized by using methoxyflurane (Pitman-Moore, Inc.) inhalation therapy. Transmitters were surgically implanted intra-peritoneally through a 10-mm incision made just lateral to the ventral midline in the abdominal region. Each incision was closed with surgical nylon sutures. Animals selected for implantation were trapped the night before surgery and released the next evening following recovery from surgery. Seven male M. meridianus and 9 male $\mathrm{M}$. tamariscinus were equipped with transmitters and radiotracked for periods of 5-12 $(8.9 \pm 0.9, \mathrm{n}=7)$ and 7-10 $(9.0 \pm 0.3, \mathrm{n}=9)$ days respectively (Mann-Whitney U-test: $U=27.5, \mathrm{p}=0.672)$. The period of monitoring depended on longevity of battery life of individual transmitters. We used a hand held 3-element Yagi antenna to locate animals. We approached gerbils until we observed an individual aboveground in the light of a headlamp. If we did not see an animal on the surface of the ground we identified the burrow with the animal inside by determining the signal location. We recorded time of location and specified whether an animal was above or below ground. Locations were marked by numbered colored flags that later were transposed to a map and assigned to $20 \times 20 \mathrm{~m}$ grid squares. We located each animal 1-3 times during the nighttime activity phase (from 21:30 to 05:30) and 1-2 times during the daylight resting time (from 08:00 to 20:00). We obtained a total of 118 telemetry fixes for M. meridianus and 220 telemetry fixes for M. tamariscinus. Locations occurring during the first night after surgery were excluded from analysis. We also excluded repeated diurnal locations, since they lacked independence. Number of nocturnal locations per individual was similar between species ( 11 . $3 \pm 1.0$, range $=7-17$ for $M$. meridianus and $11.3 \pm 0.8$, range $=9-15$ for $\mathrm{M}$. tamariscinus; 
$U=31.0, \mathrm{p}=0.958$ ). To minimize effect of autocorrelation in radiolocation data (Swihart and Slade 1985) we included successive telemetry fixes in our analysis that were separated by at least 1 hour (Ribble and Stanley 1998). Thus, the interval between successive nocturnal fixes ranged from 1 to 4 hours $(2.2 \pm 0.2)$ for $M$. meridianus and from 1 to 5 hours $(2.9 \pm 0.2)$ for M. tamariscinus. At the conclusion of the radiotracking session transmitters were removed using the same surgical procedure described earlier, and animals were released to the study site after full recovery. To control for the effect of surgery we compared body mass of gerbils before and after live-trapping and radiotracking sessions. No significant differences in body mass were revealed in M. meridianus or in M. tamariscinus ( $\mathrm{U}=26.0, \mathrm{p}=0.522$ and $U=16.0, \mathrm{p}=0.759$, respectively) upon comparison of individuals employed in the two procedures.

\section{Data analysis}

Trapping data were analyzed for animals with $\geq 5$ captures. Sixteen males and 11 females of M. meridianus and 8 males and 18 females of M. tamariscinus met this criterion. The number of individual captures did not differ between species $[8.4 \pm 0.6$ and $9.6 \pm 1.5$ captures per individual for males, respectively (Mann-Whitney U-test: $U=59.5, p=0.783$ ); $12.2 \pm 1.4$ and $12.3 \pm 1.2$ for females, respectively (Mann-Whitney: $U=95.0, \mathrm{p}=0.850$ )].

We analyzed ranging patterns using various techniques. To assess multiday ranging patterns we estimated number of grid squares visited by an individual (NGS), 100\% area of minimum convex polygon (MCP) as a measure of home range size, mean squared distance from the home range center (MSD or $\mathrm{r}^{2}$ ) as a measure of dispersion around center of activity, and maximal distance between individual locations (length of range, LR) from both trapping and radiotracking data sets (Burt 1940, Schoener 1981, Slade and Swihart 1983, Swihart and Slade 1985, Spencer et al. 1990, Swihart 1992, Slade and Russell 1998).

For each male equipped with a radiotransmitter we estimated number of burrows used as shelters at night and as resting sites during daytime. Males tended to change resting burrows periodically. We assessed residence time for each resting burrow as a period of consecutive days during which an individual rested in the daytime in the same burrow. Only burrows with exactly fixed dates of "checking in" and "checking out" were included in our analysis.

We used distance measures from radiotracking data only to assess temporal dependence of distance traversed by contrasting short-term (daily, within activity cycle) and long-term (multiday, between activity cycles) movement patterns in males. Distance measures were shown to highly correlate with the home range size and can be pooled for animals with few locations to estimate the mean for a category (Slade and Swihart 1983, Slade and Russell 1998). Since there were few daily observations for each individual male gerbil, we used distance measures as correlates of home range and pooled individual data to estimate the mean for categories of movements as follows: (1) distance between successive locations during the single night, (night movement, NMv), (2) distance between night individual location and resting burrow (distance from the burrow, DstB), (3) distance between first night individual locations on subsequent days (daily movement, DMv), (4) distance between consecutive resting ("day") burrows (resting burrow relocation shift, RBSh), and (5) distance between first and last location of individual (multiday movement, MDMv). Thus, time interval for distance measures varied from few hours for NMv and DstB to 5-12 days for MDMv.

To assess site fidelity we used a modification of Spencer's procedure (Spencer et al. 1990) from Animal Movement module 2.0 for ArcView 3.2. (Hooge et al. 1999). We compared actual MSD of individual multiday movements with those simulated by random process (100 replicates) and then assessed the portion of simulated movements with higher MSD than those from actual movements. High portion of simulated MSD greater than actual MSD indicates concentrated and stable space usage. In addition, to assess stability of multiday home ranges, we used the Linearity index (LI), ie the distance between the animal's first and last position divided by the total distance traveled, where linear paths produce $L I=1$, while LI $<1$ indicate non-linear, meandering movements. High values of LI indicate tendency to shift the home range, whereas low values correspond to stationary home ranges (Danielson and Swihart 1987, Spencer et al. 1990). 
Since female dispersion may affect male ranging patterns (see Introduction) we assessed density and distribution of females within the grid. We used nearest neighbors analysis (Clark and Evans 1954) for complete survey from Animal Movement module 2.0 for ArcView 3.2 (Hooge et al. 1999) to assess pattern of distribution of females' captures and centers of activity (CA) taken as geometric centers of the home ranges. Because our data did not conform to the assumptions of normality, we used non-parametric tests (Mann-Whitney U-test and Kruskal-Wallis ANOVA) for cross-species comparisons. All values are presented as mean \pm SE. We used significance level of $p<0.05$.

\section{Results}

\section{Distribution of females}

The number of adult females of Meriones meridianus and M. tamariscinus within 12 ha study grid was similar (19 or 1.6 individuals/ha and 25 or 2.1 individuals/ha, respectively), and females of two species occupied similar areas within the grid as indicated by number of visited traps that did not differ between species (63 of total 300 and 70 of 300 for female M. meridianus and M. tamariscinus, respectively; $\left.\chi^{2}=0.47, \mathrm{p}=0.491\right)$. In both species, nearest neighbors analysis revealed a similar uniform pattern of distribution $(R=1.3,|z|=2.7$, $\mathrm{p}<0.01$ for distribution of centers of activity (CAs) and $\mathrm{R}=1.26,|z|=6.17$, $\mathrm{p}<0.0001$ for distribution of captures in M. meridianus and $\mathrm{R}=1.67,|z|=5.7$, $\mathrm{p}<0.0001$ for distribution of CAs and $\mathrm{R}=1.62,|z|=18.1, \mathrm{p}<0.0001$ for distribution of captures in M. tamariscinus).

\section{Ranging}

Females of M. meridianus tended to range more widely than females of M. tamariscinus as indicated by significantly greater length of multiday range and mean squared distance from the range center (Table 1). Ambient significance difference was also revealed in the area of the home range that was twice as large in female $M$. meridianus than in $M$. tamariscinus.

Males of both species ranged much more widely than females (Table 1) and exhibited similar uneven space-use patterns with 1 to 4 peaks of utilization distribution (Figs 1 and 2). No differences between species in multiday male ranging patterns were revealed by either trapping or radiotracking (Table 1). Males of M. meridianus and M. tamariscinus visited the same number of grid squares, and their home ranges were of similar size as estimated by minimum convex polygon, maximal distance between locations, and mean squared distance from the center.

\section{Site fidelity}

On average, $94.4 \pm 2.8 \%$ of randomly simulated MSD of male M. meridianus $(n=7)$ and $98.0 \pm 3.0 \%$ of that of male M. tamariscinus $(n=9)$ were higher than MSD values from actual multiday movements (Mann-Whitney U-test: $U=30.0$, $\mathrm{p}=0.874$ for cross-species comparison). Only for 1 of 7 males of $M$. meridianus and for 2 of 9 males of $M$. tamariscinus the proportions of the simulated movement 
Table 1. Ranging patterns in Meriones meridianus and M. tamariscinus as revealed by radiotracking and trapping in Kalmykia, southern Russia, 23 May - 20 June 2000. NGS - number of grid squares visited, MCP - minimum convex polygon area, MSD - mean squared distance from the home range center, LR - length of multiday home range. The significant differences between sexes within species by means of Mann-Whitney $U$-test: ${ }^{*}-p<0.05,{ }^{* *}-p<0.01,^{* * *}-p<0.001$.

\begin{tabular}{|c|c|c|c|c|c|c|c|}
\hline \multirow{3}{*}{ Technique } & \multirow{3}{*}{ Method } & \multirow{2}{*}{\multicolumn{2}{|c|}{$\begin{array}{l}\text { M. meridianus } \\
\text { Mean }=\mathrm{SE}(n)\end{array}$}} & & & & \\
\hline & & & & \multicolumn{2}{|c|}{$\begin{array}{l}\text { M. tamariscinus } \\
\text { Mean } \pm \operatorname{SE}(n)\end{array}$} & \multicolumn{2}{|c|}{$\begin{array}{l}\text { Mann-Whitney U-test for } \\
\text { cross-species comparison, } p\end{array}$} \\
\hline & & Males & Females & Males & Females & Males & Females \\
\hline \multirow[t]{2}{*}{ NGS } & radiotracking & $8.6 \pm 0.7(7)$ & & $9.0 \pm 0.8(9)$ & & 0.525 & \\
\hline & trapping & $4.4 \pm 0.5(16)$ & $4.8 \pm 0.6(11)$ & $4.6 \pm 0.5(8)$ & $3.8 \pm 0.5(18)$ & 0.736 & 0.192 \\
\hline \multirow[t]{2}{*}{ 100\% MCP (ha) } & radiotracking & $0.51 \pm 0.11(7)$ & & $0.55 \pm 0.09(9)$ & & 0.791 & \\
\hline & trapping & $0.25 \pm 0.05$ & $0.13 \pm 0.03(10)$ & $0.30 \pm 0.08(6)$ & $0.07 \pm 0.01(13)^{* *}$ & 0.409 & 0.067 \\
\hline \multirow[t]{2}{*}{$\operatorname{MSD}\left(\mathrm{m}^{2}\right)$} & radiotracking & $2090 \pm 406(7)$ & & $2410 \pm 666(9)$ & & 0.711 & \\
\hline & trapping & $2121 \pm 408$ & $728 \pm 138(11)^{* *}$ & $2623 \pm 705(6)$ & $321 \pm 50(18)^{* *}$ & 0.564 & 0.019 \\
\hline \multirow[t]{2}{*}{$\mathrm{LR}(\mathrm{m})$} & radiotracking & $132 \pm 17(7)$ & & $143 \pm 20(9)$ & & 0.874 & \\
\hline & trapping & $96 \pm 11(16)$ & $62 \pm 7(11)^{*}$ & $101 \pm 13(8)$ & $42 \pm 5(18)^{* * *}$ & 0.691 & 0.021 \\
\hline
\end{tabular}


A. Tchabovsky et al.

M. meridianus

380
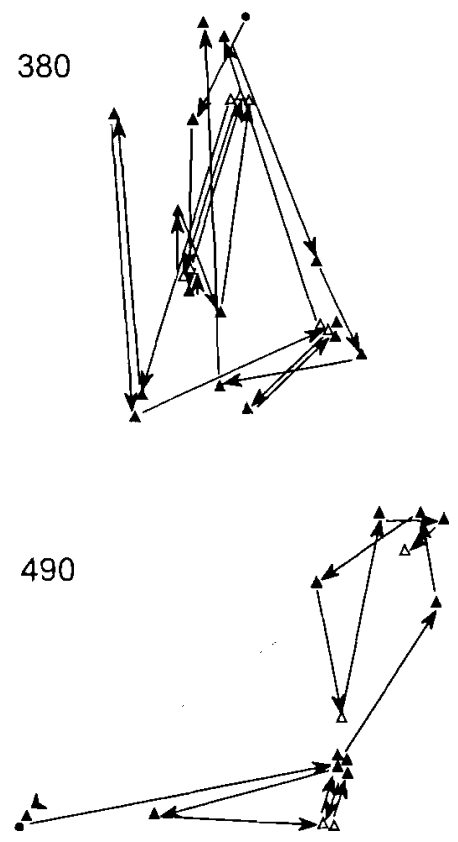

1029
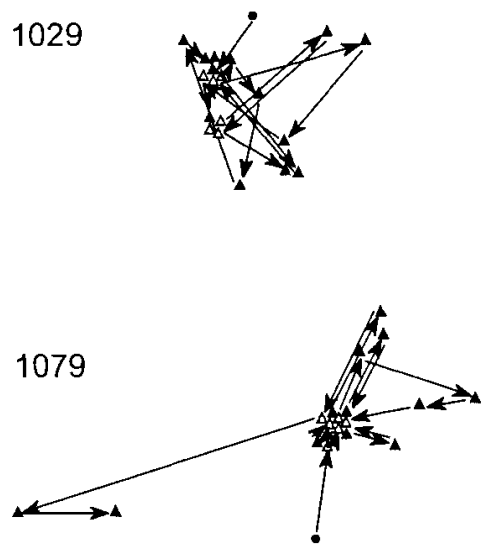

M. tamariscinus

1028

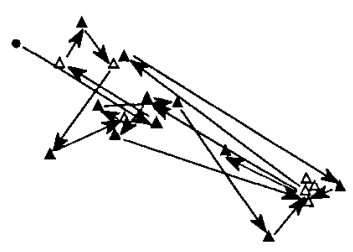

1024

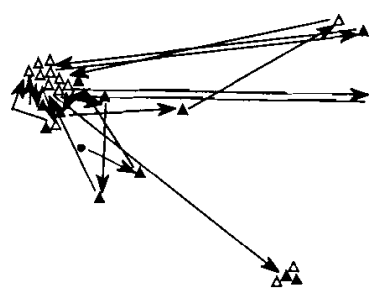

1014

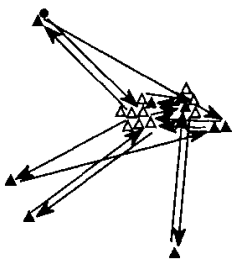

1037

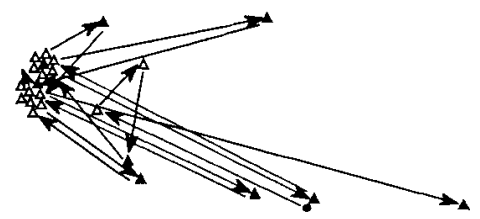

$20 \mathrm{~m}$

Fig. 1. Examples of multiday movements of male Meriones meridianus and M. tamariscinus as revealed by radiotracking in Kalmykia (southern Russia) in May-June 2000. Open triangles indicate day-time locations, closed triangles indicate night-time locations, closed circles indicate locations of release. Numbers means individual males. 


\section{M. meridianus}

490

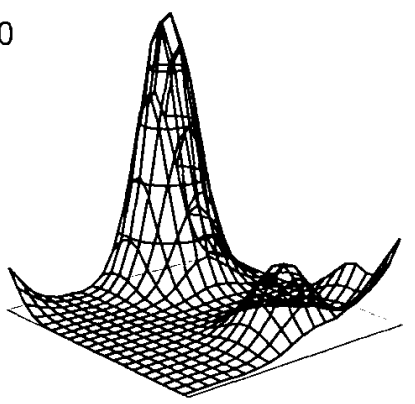

1061

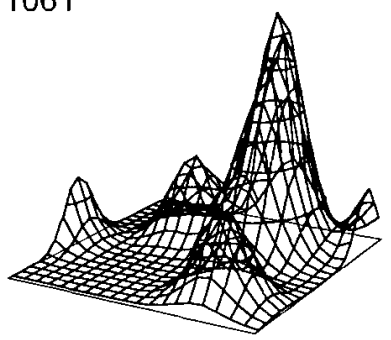

1029

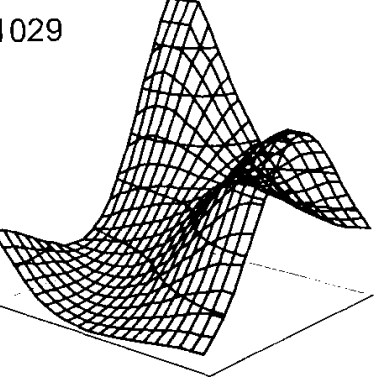

1079

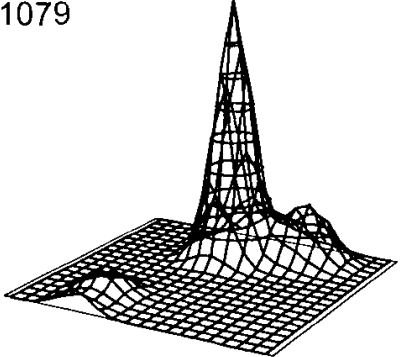

\section{M. tamariscinus}
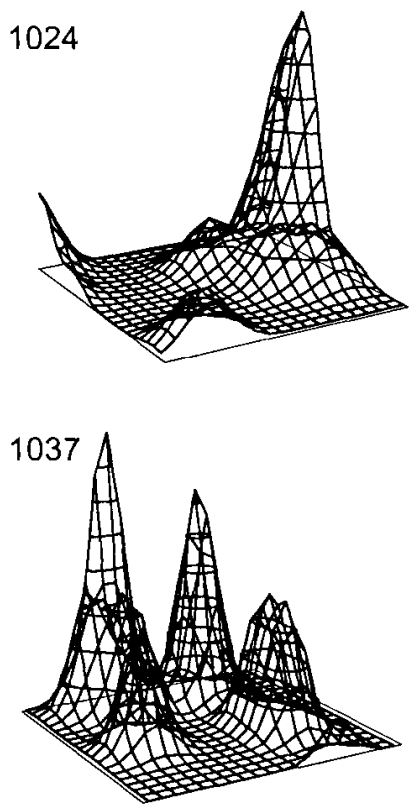

1038

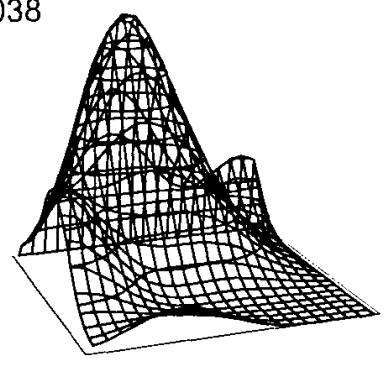

1020

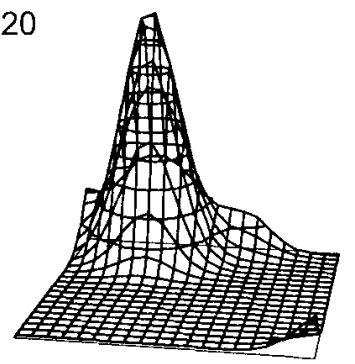

Fig. 2. Examples of utilization density distribution of male Meriones meridianus and M. tamariscinus radiolocations. Kalmykia (southern Russia) in May-June 2000. Only night locations were considered. Least squares cross-validation adjustment of smoothing factor was performed by the computer program The Home Ranger 1.5 by Hovey (1999). Each square represents about $16 \mathrm{~m}^{2}$. Numbers means individual males. 
paths with greater MSD values than actual MSD were less than 95\% indicating strong site fidelity and more constrained than random space use in both species. Likewise, males of both species exhibited similarly low linearity indices of multiday home ranges $(0.12 \pm 0.03$ and $0.12 \pm 0.03$ for $\mathrm{M}$. meridianus and M. tamariscinus, respectively; $U=31.0, \mathrm{p}=0.958$ ) indicating non-linear meandering multiday movements.

\section{Temporal dependence of movements}

Both male $M$. meridianus and male $M$. tamariscinus traversed similar distances between successive locations in the same night, between first locations recorded on consecutive nights, and when changing resting burrows. Also, they were found at night at similar distances from their resting burrows. Finally, no between-species differences were revealed in multiday distances between first and last location of radiotracked individuals (Fig. 3). Short-term (within a single activity cycle) and long-term (between activity cycles) movement distances were similar in both species; no significant variation among five categories of ranging distances (single night movements, distance from resting burrow, daily movements, distance of resting burrow relocation, and distance between first and last location) was revealed in either M. meridianus (Kruskal-Wallis test: $\mathrm{H}=5.14$, $\mathrm{df}=4, n=144$, $p=0.274)$ or M. tamariscinus $(H=7.18, \mathrm{df}=4, n=197, p=0.127)$. Multiday

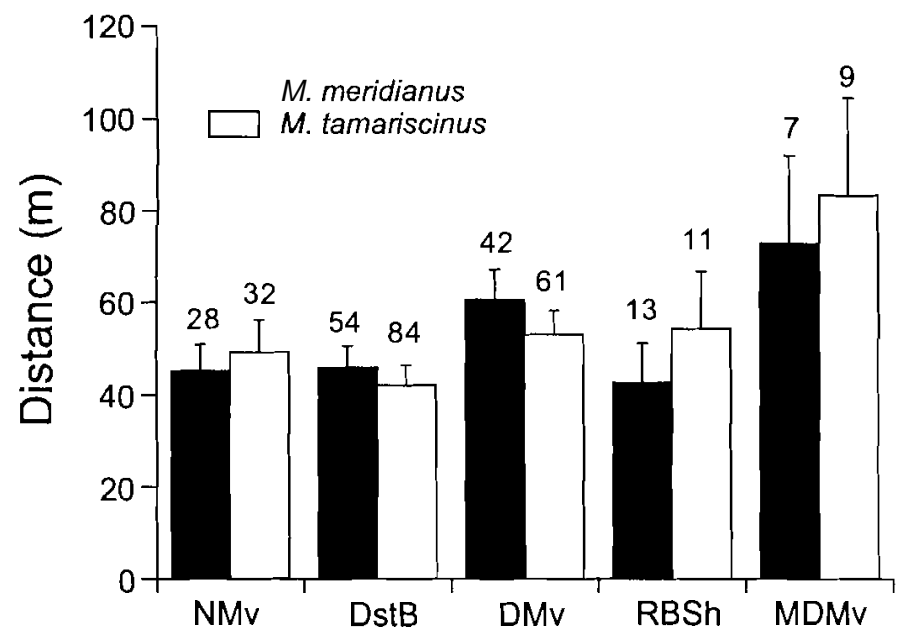

Fig. 3. Distance measures (mean $+\mathrm{SE}$ ) for male Meriones meridianus and M. tamariscinus from radiotracking data in Kalmykia (southern Russia) in May-June 2000. Figures above bars show $n$. NMv - night movement, DstB - distance from the burrow, DMv - daily movement, RBSh - resting burrow relocation shift, MDMv - multiday movement. See 'Material and methods' for details on movement categories. No significant between-species differences were revealed in either distance category (Mann-Whitney U-test: $\mathrm{p}=0.322-0.870$ ). Multiday movement distance did not differ from daily (DMv) or single-night (NMv) movement distances in either M. meridianus $(p=0.520$ and $p=0.174$, respectively) or $M$. tamariscinus ( $p=0.166$ and $\mathrm{p}=0.135$, respectively). 
movement distances between first and last individual location tended to be slightly greater, though far from significant, than single-day or single-night movements in both species (Fig. 3).

\section{Use of burrows}

Both male M. meridianus and M. tamariscinus used 1 to 3 burrows as day-time resting sites throughout the period of radiotracking $(2.3 \pm 0.4, \mathrm{n}=7$ and $2.0 \pm 0.2$, $n=9$, respectively; Mann-Whitney U-test:: $U=23.5, p=0.397$; Fig. 1). Switching of resting burrows always occurred during the night. Time of residence at resting burrows was significantly shorter in M. meridianus, than that in M. tamariscinus ( $3.4 \pm 0.7$ and $5.3 \pm 0.5$ days, respectively; $U=10.5, \mathrm{p}=0.043$ ).

Number of shelter burrows used at night varied from 2 to 7 and from 3 to 11 in midday and tamarisk gerbils respectively $(5.1 \pm 0.7$ and $6.6 \pm 1.0 ; U=36.0, \mathrm{p}=$ 0.561 ). Both species used shelters during hours of darkness at similar rates; males of M. meridianus and $M$. tamariscinus were located underground during the night in $44 \pm 10 \%$ and 45 a $7 \%$ of all telemetry fixes during darkness $(U=30.0, \mathrm{p}=$ $0.874)$.

\section{Discussion}

As predicted from the between-species differences in the diets females of granivorous M. meridianus tended to range more widely than females of folivorous M. tamariscinus. In contrast, we found no evidence that species specific diet contributed to determining ranging patterns in males. Males of both species exhibited much larger home ranges than females suggesting that movements of males are not solely determined by nutritional needs, but are obviously associated with searching for mates. Moreover, both trapping and radiotracking data showed similar ranging patterns in males of both species. Male M. meridianus and M. tamariscinus exhibited uneven space use with one or more peaks of utilization distribution density, used a similar number of sheltering and resting burrows, exhibited home ranges of similar size, traversed similar distances during and between activity phases, and moved away from the main burrow at similar distances during nocturnal activity phase. These similarities suggest that ranging patterns of males of both granivorous and folivorous species were solely determined by distribution of females (that was similar between species in our study), whereas between-species differences in feeding habits had no significant effect on male ranging. Nevertheless, striking similarities between species in patterns of home range-use by males seem rather strange for species that are quite different, in terms of dietary preferences and nutritional needs. Low-quality diet of folivorous species such as M. tamariscinus should constrain regular energetically costly long-distance movements and extensive home range use which is typical and energetically justifiable for granivores, such as M. meridianus that feed on 
high-quality food items. Such food can meet energetic expenses required for long-distance movements and wide ranging patterns.

Herbivorous gerbils usually exhibit a "residence-relocation-residence" spacing pattern (Kucheruk et al. 1972, Daly and Daly 1975, Krasnov et al. 1996). This pattern is characteristic if an individual that forages intensively in one small patch of low-quality food moves to another one when food resources are depleted. For example, small drifting home ranges were observed in folivorous sand rats that could not maintain themselves for a long period within the same patch of low-quality food and had to relocate home ranges (Daly and Daly 1974). Such drifting home range use should be manifested by temporal dependence of distance measures with short-term movements being shorter than long-term multiday movements. However, we did not observe such "two [short-term and long-term] component" (Krasnov et al. 1996) movement patterns, that suggests alternation of short- and long-distance movements in folivorous M. tamariscinus. No temporal dependence of distance traveled was revealed in either species, and distances of burrow relocation or multiday distances did not exceed daily or single night movements. Males of both species of gerbils traversed similar and great enough distances regardless of time interval for distance measures. Moreover, high significant proportion of non-random movements coupled with very low linearity indices for multiday home ranges indicate concentrated space use, strong site fidelity, and stationary home ranges in both granivorous and folivorous species during the entire period of observations. In other words, for both species of gerbils relocation of resting burrows occurred within the entire home range; it was not associated with the shift of the home range that remained stable and was inspected nightly during the entire period of observations. Such extensive patterns of space-use is rather characteristic of granivorous rodents that cover long distances searching for scattered high-quality food items in order to compensate energy expenditures necessary for wide ranging. Thus, why males of folivorous M. tamariscinus allow themselves wide ranging in granivorous manner remains unclear and requires nutritionally based explanation.

"Granivorous" ranging patterns performed by males of folivorous M. tamariscinus may correspond to a species specific foraging behavior. Nutritional attributes of M. tamariscinus reflect a very high degree of food selectivity (Magomedov and Akhtayev 1993). Tamarisk gerbils are one of the most folivorous and mesophilic species among the family (Pavlinov et al. 1990). Unlike the majority of gerbils, this species exhibits high water requirements, and like other gerbils is poorly adapted for digestion of cellulose of plants (Abaturov and Khasheva 1995). Thus, tamarisk gerbils show a high degree of food selectivity; food items consumed include young leaves and generative parts of plants rich in water and nutrients with relatively low fiber content. As a result, while foraging tamarisk gerbils allocate a major portion of activity to searching and investigating for food; about $90 \%$ of feeding bouts are less than 5 seconds in duration, interrupted by movements and exploratory activity (Popov and Tchabovsky 1998). Thus, folivory in M. tamariscinus is analogous to 
granivory in other species in which foraging tactics allocate searching for scattered high-quality food items. Similar observations of high food selectivity explain the large home ranges and long distances traversed in the folivore primate Lepilemur edwardsi of Madagascar that feeds on relatively high-quality, young leaves and flowers (Warren and Crompton 1997). This contrasts to smaller ranges of the syntopic primate Avahioccidentalis that exhibits nonselective feeding on relatively low-quality, but ubiquitous, mature and old leaves. Thus, food selectivity of folivorous M. tamariscinus appears to be an important factor allowing wide ranging by males during breeding season.

Acknowledgements: We would like to express our gratitude to Professor S. Shilova who encouraged and supported the study and invited JFM to join our research team. We thank G. Bazykin, L. Savinetskaya, N. Ovchinnikova, V. Neronov and V. Kuznetsov who helped to collect data in the field. We acknowledge support and facilities provided by Elista Plague Control Station, especially its Director A. V. Podsvirov and local manager V. M. Leont'ev. T. Karimova assisted in data treatment and analysis. Comprehensive discussions with N. Shchipanov helped to improve the earlier draft of the manuscript. Many thanks to three anonymous referees who read and provided constructive critique of later version of this paper. The study was funded by International Science and Technology Center (grant number 1174-00 to AT and DA), the Russian Foundation for Basic Research (01-04-48358 to AT), and the Federal Program "Integrazia" (E-0308 to AT). The M. Lazear Research Endowment (CMNH) provided funding for travel to Kalmykia for JFM. Field work was partly supported by V. Bankin.

\section{References}

Abaturov B. D. and Khasheva M. G. 1995. Digestion of green vegetation by rodents of various food specialization in relation to plant vegetative phase. Zoologicheskii Zhurnal 74: 132-141. [In Russian with English summaryl

Ascaray C. M. and McLachlan A. 1990. Home range of Gerbillurus paeba in a southern African coastal dunefield. Zeitschrift fiir Saugetierkunde 55: 399-406.

Burt W. H. 1940. Territorial behavior and populations of some small mammals in southern Michigan. Miscellaneous Publications of the Museum of Zoology, University of Michigan 45: 1-58.

Clark P. J. and Evans F. C. 1954. Distance to nearest neighbor as a measure of spatial relationships in populations. Ecology 35: 445-453.

Clutton-Brock T. H. 1989. Mammalian mating systems. Proceedings of the Royal Society of London, Series B, 236: 339-372.

Daly M. and Daly S. 1974. Spatial distribution of a leaf-eating Saharan gerbil (Psammomys obesus) in relation to its food. Mammalia 38: 591-603.

Daly M. and Daly S. 1975. Behavior of Psammomys obesus (Rodentia: Gerbillinae) in the Algerian Sahara. Zeitschrift fiir Tierpsychologie 37: 298-321.

Danielson B. J. and Swihart R. K. 1987. Home range dynamics and activity pattern of Microtus ochrogaster and Synaptomys cooperi in syntopy. Journal of Mammalogy 68: 160-165.

Davies N. B. 1991. Mating systems. [In: Behavioural ecology: an evolutionary approach. J. R. Krebs and N. B. Davies, eds]. Blackwell Scientific Publications, Oxford: 263-294.

Gromov V. S., Tchabovsky A. V., Paramonov D. V. and Pavlov A. P. 1996. The seasonal dynamics of demographic and spatial structure in the wild populations of tamarisk gerbil (Meriones lamariscinus) in Southern Kalmykia. Zoologicheskii Zhurnal 75: 413-428. [In Russian with English summary]

Harestad A. S. and Bunnell F. L. 1979. Home range and body weight - a reevaluation. Ecology 60: 389-402. 
Hooge P. N., Eichenlaub W. and Solomon E. 1999. The animal movement program. USGA, Alaska Biological Center.

Hovey F. W. 1999. The Home Ranger. Ursus Siftware, Revelstoke, BC Canada

Karulin B. E., Nikitina N. A., Khlyap L. A., Litvin V. Y., Albov S. A., Okhotskii Y. B. and Sushkin N. D. 1974. Some results and perspectives of applying radioisotopes to study small mammals, reservoir hosts of infections. [In: Theriology. V. E. Sokolov, edl. Volume 2. Nauka, Novosibirsk: 218-226. [In Russianl

Kelt D. A. and Van Vuren D. H. 2001. The ecology and macroecology of mammalian home range area. The American Naturalist 157: 637-645.

Krasnov B. R., Shenbrot G. I., Khokhlova I. S., Degen A. A. and Rogovin K. A. 1996. On the biology of Sundevall's jird (Meriones crassus Sundevall, 1842) (Rodentia: Gerbillidae) in the Negev Highlands, Israel. Mammalia 60: 375-391.

Kucheruk V. V., Kulik I. L. and Dubrovsky Yu. A. 1972. Rhombomys opimus Licht. is a life form of the desert. Fauna and Ecology of Rodents 11: 5-63. [In Russianl

Mace G. M. and Harvey P. H. 1983. Energetic constraints on home-range size. The American Naturalist 121: 120-132.

Magomedov M.-R. D. and Akhtayev M.-X. R. 1993. Nutrition and population status of tamarisk gerbils (Meriones tamariscinus) in relation to dynamics of food resources. Zoologicheskii Zhurnal 72: 101-111. [In Russian with English summaryl

McNab B. K. 1963. Bioenergetics and the determination of home range size. The American Naturalist 97: $133-140$.

Neronov V. V., Tchabovsky A. V., Aleksandrov D. Yu. and Kasatkin M. V. 1997. Spatial distribution of rodents under conditions of anthropogenic dynamics of vegetation in southern Kalmykia. Russian Journal of Ecology 28: 328-334.

Ostfeld R. S. 1985. Limiting resources and territoriality in microtine rodents. The American Naturalist 126: $1-15$.

Ostfeld R. S. 1990. The ecology of territoriality in small mammals. Trends in Ecology and Evolution 5: 411-415.

Pavlov A. N. 1959. Patterns of reproduction of gerbils, Meriones meridianus and $M$. tamariscinus in Northwestern Ciscaspian area. Zoologicheskii Zhurnal 38: 1876-1885. [In Russian with English summary]

Pavlinov I. J., Dubrovsky Y. A., Rossolimo O. L. and Potapova E. G. 1990. Gerbils of the world. Nauka, Moscow: 1-363. [In Russianl

Popov S. V., Tchabovsky A. V., Shilova S. A. and Shchipanov N. A. 1989. Mechanisms of the formation of spatio-ethological structures of populations of midday gerbils in normal and under artificially reduced numbers. [In: Fauna and Ecology of Rodents 17. V. E. Sokolov, ed]. Moscow University Press, Moscow: 5-58. [In Russian]

Popov S. and Tchabovsky A. 1998. Behavior of Meriones tamariscinus in the wild. Russian Journal of Zoology 2: 161-168.

Reichman O. J. and Price M. V. 1993. Ecological aspects of heteromyid foraging. [In: Biology of the Heteromidae. H. H. Genoways and J. H. Brown, edsl. The American Society of Mammalogists, Special Publication No. 10: 539-574.

Ribble D. 0 . and Stanley S. 1998. Home ranges and social organization of syntopic Peromyscus boylii and P. truei. Journal of Mammalogy 79: 932-941.

Schoener T. W. 1981. An empirically based estimate of home range. Theoretical Population Biology 22: $281-325$.

Shilova S. A., Tchabovsky A. V., Neronov V. V. and Aleksandrov D. Y. 2000. Monitoring of vegetation and rodents populations under diminution of grazing in the South of Kalmykia. [In: Biodiversity and dynamics of ecosystems in northern Eurasia. M. P. Moshkin, ed]. Novosibirsk: 286-288.

Slade N. A. and Russell L. A. 1998. Distances as indeces to movements and home-range size from trapping records of small mammals. Journal of Mammalogy 79: 346-351. 
Slade N. A. and Swihart R. K. 1983. Home range indices for the hispid cotton rat (Sigmodonhispidus) in Northern Kansas. Journal of Mammalogy 64: 580-590.

Spencer S. R., Cameron G. N. and Swihart R. K. 1990. Operationally defining home range: temporal dependence exhibited by hispid cotton rats. Ecology 71: 1817-1822.

Swihart R. K. 1992. Home-range attributes and spatial structure of woodchuck populations. Journal of Mammalogy 73: 604-618.

Swihart R. K. and Slade N. A. 1985. Testing for independence of observations in animal movements. Ecology 66: 1176-1184.

Tchabovsky A. V. and Aleksandrov D. Y. 1996. Spatial organization of two gerbillidae species, Meriones meridianus and Meriones tamariscinus, community in Kalmykia. Zoologicheskii Zhurnal 75: 1842-1851. [In Russian with English summary]

Warren R. D. and Crompton R. H. 1997. A comparative study of the ranging behaviour, activity rhythms and sociality of Lepilemur edwardsi (Primates, Lepilemuridae) and Avahi occidentalis (Primates, Indriidae) at Ampijoroa, Madagascar. Journal of Zoology, London 243: 397-415.

Received 26 November 2002, accepted 1 October 2003.

Associate Editor was Andrzej Zalewski. 